\title{
CARLOS GAGINI Y EL ROMANTICISMO \\ EN COSTA RICA
}

\author{
POR \\ MARIA EUGENIA ACUÑ̄A M. \\ Universidad de Costa Rica
}

Carlos Gagini es uno de los forjadores de la literatura costarricense. Escritor prolífico como pocos, de vasta cultura, fue el prototipo del hombre costarricense ilustrado que tanto contribuyó al fortalecimiento de la nación en estos primeros tiempos de consolidación institucional.

Nace en San José el 15 de mayo de 1865, de madre costarricense y padre de origen suizo. En Costa Rica esta época se caracterizó por el desarrollo de la labor educativa impulsada por el gobierno de Jesús Jiménez, presidente en ejercicio desde 1863. El floreciente clima intelectual favoreció las inclinaciones del joven Gagini, quien no sólo se nutrió de las influencias de un hogar abierto a la cultura universal, sino que desde muy temprana edad se convirtió en un ávido lector, especialmente de los clásicos franceses.

$\mathrm{Su}$ versatilidad como escritor lo llevó a experimentar en diversos campos del quehacer literario, con éxito en todos. Como poeta, introdujo el romanticismo en el país; como narrador, logra captar los aspectos más significativos de la cultura costarricense; como dramaturgo es uno de los primeros que incursionó en el teatro con temática nacional, propiciando el costumbrismo; su labor filológica y lingüística trascendió las fronteras costarricenses.

Tiene, además, la importancia de entrever la posibilidad de utilizar la obra literaria como instrumento para abordar algunos problemas nacionales e internacionales de su época. En este aspecto fue un escritor comprometido plenamente con su circunstancia histórica; en la temática de su obra refleja no sólo su inquietud por el panorama político nacional, sino también por el destino de la América Latina.

En él convergen diferentes influencias de los movimientos literarios que tuvieron repercusión en las últimas décadas del siglo xIX y primeras del xx; por ello, se le puede señalar como escritor de transición. 
Su quehacer literario se inicia con su producción poética. A la edad de diecisiete años publica su primer poema, y durante su vida continuará haciéndolo, alternando con otros géneros, especialmente ensayo y narrativa.

Gagini, como poeta, es menos conocido que como narrador; por esta razón, el objetivo que buscamos es destacar la trascendencia que su poesía tuvo en la evolución de las letras costarricenses.

Menos extensa que su obra en prosa, su producción poética es de igual valor significativo que sus novelas.

Reiteradamente, la crítica ha afirmado que en Costa Rica no existió un movimiento romántico, que más bien lo que sucedió fue la influencia, en algunos escritores costarricenses, de románticos tardíos, especialmente de Gustavo Adolfo Bécquer ${ }^{1}$. Contrariamente a lo anterior, el estudio de las manifestaciones poéticas, no sólo de Gagini, sino de otros escritores contemporáneos suyos, permite señalar no solamente influencias de algunos románticos descollantes, sino la presencia de un romanticismo no tan desarrollado como en el resto de Hispanoamérica, pero con los rasgos más sobresalientes del movimiento, especialmente en su vertiente sentimental.

El romanticismo cobra importancia en Hispanoamérica a partir de la primera década del siglo xix ${ }^{2}$; en Costa Rica aparece aún más tardíamente, en las últimas décadas de ese mismo siglo. En 1890, Máximo Fernández publica la primera antología de poetas costarricenses, Lira costarricense, en donde recoge los aportes de los escritores más destacados, que ya muestran algunos elementos de la escritura romántica. Un año después aparece el segundo tomo de la Lira, hecho que pone de manifiesto el interés que existía en el medio costarricense por esas manifestaciones culturales.

Este mismo año, 1891, Gagini publica su primer poema, «El gran galeoto», inspirado en un tema romántico por excelencia. Desde este momento, la moda literaria propiciará la aparición de abundantes poemas inspirados formal y temáticamente en el gusto de la tendencia. Las revis-

${ }^{1}$ El crítico más destacado de la literatura costarricense, Abelardo Bonilla, afirma que «es interesante anotar que las letras costarricenses, retrasadas en los siglos anteriores con relación a las demás o a la mayoría de los países hispanoamericanos, hasta ignorar del todo el movimiento romántico, coincidieron, sin embargo, con los pueblos más avanzados al iniciar el movimiento realista», en Historia de la literatura costarricense, 2. edición (San José: Editorial Costa Rica), p. 167.

${ }^{2}$ Alfredo Veiravé sostiene que: «El romanticismo hispanoamericano, como movimiento literario, está vinculado directamente a un largo período que va desde 1830 hasta 1860», en Literatura hispanoamericana (Buenos Aires: Kapelusz, 1976), p. 93. Cfr., además, Emilio Carilla, El Romanticismo en América Latina (Madrid: Editorial Gredos, 1958), p. 2. 
tas literarias de esa época son el vehículo de expresión de todas las inquietudes líricas y confirman que Gagini fue secundado en su afán renovador ${ }^{3}$.

El auge en las letras costarricenses coincide con la declinación del romanticismo en el resto de Hispanoamérica, por lo que es importante señalar el carácter tardío del movimiento en el país.

En este período el romanticismo ya había entrado, en las restantes naciones, en una corriente sentimental que intentaba conmover al lector e imponer el predominio de lo subjetivo. El paisaje se ha idealizado lo suficiente como para anunciar los valores regionales que harán triunfar el costumbrismo de fuerte sabor local. En Costa Rica, romanticismo y costumbrismo conviven, precisamente por la diferente evolución del movimiento.

El aporte de Gagini es introducir en la literatura costarricense los motivos y preferencias del romanticismo europeo y latinoamericano, impulsando un romanticismo sentimental que, aunque tardío, situó las letras nacionales dentro de la totalidad de corrientes espirituales de su época.

En la producción poética de este autor pueden captarse afinidades con los románticos europeos e hispanoamericanos más destacados. Gran conocedor de la literatura francesa e inglesa, traductor de obras de Víctor Hugo, Longfellow, Byron ${ }^{4}$, ferviente admirador de los españoles Bécquer, Zorrilla y Espronceda, así como de algunos latinoamericanos, supo asimilar los rasgos más sobresalientes de sus obras. Especialmente los latinoamericanos Andrés Bello y Ricardo Palma, son de amplia significación en su poesía. Con Ricardo Palma sostuvo una abundante correspondencia que robusteció sus lazos intelectuales.

Andrés Bello es su maestro en el gusto por los temas nacionales; aunque el venezolano es neoclásico en cuanto a la orientación formal, es innegable su condición de precursor del romanticismo en América. Las influencias de Bello y Palma en la poesía de Gagini son reveladoras de esta admiración.

Gagini, de veinte años, escribe una de sus primeras poesías, titulada

${ }^{3}$ Basta consultar las revistas Costa Rica Ilustrada o Páginas Ilustradas, o periódicos de la época, para confirmar esta afirmación. No solamente los costarricenses, sino algunos escritores centroamericanos y mexicanos, publican sus poemas de contenido romántico.

${ }^{4}$ Según Jaime Espinar, en su obra El Romanticismo (Buenos Aires: Editorial Atlántida, 1947), ésta fue una poesía apegada a modelos europeos en las formas y hasta en el espíritu, pues Víctor Hugo fue una epidemia, tal vez necesaria, en el romanticismo. Evolución de la poesía patriótica - que sigue cánones románticoscondena a los tiranos, el poeta se compromete a vivir y a sufrir y a padecer en medio de un paisaje exótico (pp. 61-65). 
"Costa Rica» ${ }^{5}$, canto de exaltación a los valores patrios, a la belleza de la naturaleza costarricense y a sus productos. Este poema presenta un núcleo significativo semejante al de la oda de Bello «La agricultura de la zona tórrida». Coinciden los poemas en el tono elegíaco, de exaltación del yo lírico que enumera las bondades de la tierra que admira, así como la libertad y el progreso.

Bello dice:

Tú tejes al verano tu guirnalda de granadas espigas; tú la uva das a la hirviente cuba.

No de púrpura flor, o roja, o gualda a tus florestas bellas falta matiz alguno, y bebe en ellas aromas mil el viento y greyes van sin cuento ${ }^{6}$.

El poema de Gagini:

Aquí nunca se sienten los rigores del invierno aterido: con sus flores se adorna Primavera todo el año; aquí consorcio extraño forman vecinas en vergel florido las plantas orientales más preciadas con las que siempre en número crecido poblaron estas vegas encantadas ${ }^{7}$.

Este parecido con la poesía de Bello se mantiene en varios de los poemas del costarricense; no es una casual coincidencia, sino admiración y, en parte, imitación del gran escritor venezolano. El amor por la tierra es una constante en su obra lírica; en el poema «Tico», el yo lírico describe el ambiente así:

En ordenada hueste los cafetos alfombran la extensión de la campiña y en sus ramas, cual sartas de granates, las ya maduras bayas se arraciman.

${ }^{5}$ Poesía publicada, por primera vez, en 1887, en Costa Rica Ilustrada (San José, Costa Rica, año 1, núm. 7, septiembre 1887), p. 100. Posteriormente, en Vagamunderías (San José, Costa Rica, 1925), p. 10.

${ }^{6}$ Andrés Bello, Obras completas, vol. 1 (Caracas: Ministerio de Educación, 1951), pp. 66-76.

${ }_{7}$ «A Costa Rica», en Vagamunderías, p. 10. 
Las sedosas banderas de los plátanos cortan a trechos las correctas filas y el tabaco y las frescas chayoteras los troncos de los árboles cobijan ${ }^{8}$.

El descubrimiento de la belleza real del paisaje americano es uno de los motivos románticos por excelencia; la valorización del paisaje lleva al poeta romántico a solazarse con la descripción de su tierra. Esta es la actitud de Gagini, cuyo temple anímico refleja el deseo de asumir lo originario y esa nueva sensibilidad ante las formas poéticas.

La influencia de Ricardo Palma en Gagini es aún más evidente; ambos coinciden en la «nueva sensibilidad» que se manifiesta en esa búsqueda de formas novedosas para plasmar los cambios significativos que promueve el movimiento. La libertad que tanto anhelan los románticos tiene eco también en el escritor costarricense, que comparte preferencias comunes con estos escritores. Temas como desengaño, melancolia, consuelo, recuerdo, son recurrentes; exaltan las condiciones anímicas, tan importantes para los poetas románticos, ya que expresan el tema del amor imposible, la idealización de la mujer y el sufrimiento del yo lírico ante una amada y un destino más fuertes que él.

Tanto Palma como Gagini, y aun poetas posteriores, no precisamente románticos, como Darío, comparten no sólo los motivos, sino una actitud similar ante la poesía. Es una poesía elitista, de salón, que generalmente se dirige a una clase y en particular a mujeres sobresalientes, admiradas y frecuentemente amadas, siempre individualmente destacadas con una dedicatoria. Elogios que con frecuencia van dirigidos al álbum familiar y que de alguna manera señalan la función que el poeta asigna a su quehacer literario.

Es importante señalar que unido a este auge literario hay un florecimiento de la cultura costarricense. En el país no se ignora lo que ocurre en el mundo, no sólo en el campo intelectual, sino en el ámbito político y económico. Aunque retrasadas, las corrientes de pensamiento más relevantes de la época nutren a los costarricenses y los actualizan.

Este es el valioso aporte de Gagini y de otros escritores contemporáneos suyos, como Joaquín García Monge, Justo A. Facio y algunos más; promovieron la apertura de Costa Rica a la cultura universal y la pronta recepción de lo que sucedía en el campo artístico, especialmente en el quehacer poético. En este período coexisten doctrinas ideológicas y movimientos literarios. En las últimas décadas del siglo xIX el marco de referencia de la organización política lo dan las ideas liberales, que evolucio-

\footnotetext{
8 «Tico» aparece publicada por primera vez en Vagamunderías.
} 
nan hacia el positivismo; en literatura, es el romanticismo el que marca las pautas de la escritura, romanticismo que contamina cada vez más al costumbrismo y al realismo.

Con la llegada del nuevo siglo, los acontecimientos de 1898 y la independencia de Cuba, dos ideas prevalecen en el medio costarricense: la búsqueda no ya de un modelo de Estado, sino la consolidación del que se ha venido modelando, y la necesidad de fortalecer algunos valores considerados como propiamente hispanoamericanos y más concretamente nacionales, por el temor ante la política expansionista de los Estados Unidos hacia la América Latina. El panorama histórico influye, indiscutiblemente, en Gagini, quien evoluciona hacia una expresión poética de mayor contenido social. Es el momento del antinorteamericanismo, que literariamente se resuelve, en algunos casos, en críticas moderadas, en otros radicales, como se manifiesta en su poema «A la independencia de Centro América», en el que expresa:

¿Despierta Centro América, despierta!
E1 Aguila del Norte en tu divino
cielo aparece con la garra abierta
para hundirla en el pecho del latino.
¿Y su presa has de ser pueblo caduco?
¿Y aceptas resignado tu destino
con la vil mansedumbre del eunuco?

Dos vertientes temáticas se pueden señalar en la producción poética de este autor: una, la de un romanticismo sentimental, que proyectó las preferencias del movimiento; otra, más orientada hacia un romanticismo social, en la que predomina una actitud de denuncia y preocupación por los problemas políticos de la América hispana y que lo acerca más al modernismo.

La temática dominante es: el amor a la patria, la exaltación del progreso y la libertad y el temor por la posible dominación de un país más poderoso.

Se puede hablar de una toma de conciencia de estos escritores, que afloró, precisamente, al percatarse de que un nuevo colonialismo empezaba a cobrar fuerza.

Saben que a pesar de la independencia política que la mayoría de los países latinoamericanos han obtenido, sigue el predominio cultural y económico de las metrópolis. En el campo económico no hay lugar a dudas, Estados Unidos ocupa una posición hegemónica y de aquí las denuncias,

Poema publicado en Vagamunderias, p. 33. 
principalmente del modernismo; en el aspecto cultural, la permanencia de los modelos franceses e ingleses durante el siglo xix y parte del xx no dejan duda de dónde vienen las influencias.

El romanticismo aparece en América Latina como resultado de este fenómeno ${ }^{10}$.

La ruptura con las metrópolis tradicionales, España y Portugal, robustece el papel de Francia como inspiradora de los ideales intelectuales; sin embargo, se da una convivencia de tendencias y la influencia española no desaparece del todo, sólo pierde vigor.

Los escritores, y Gagini no es la excepción, son los grandes admiradores de Francia, aunque vuelven los ojos a ella un poco tarde, y más tardíamente aún los costarricenses. Gagini, en su poema «Europa», expresa esa admiración:

Por eso Francia aislada, aborrecida, representa el Progreso; y los satélites de Europa coligada, la Edad Media que se alza contra el siglo diez y nueve ${ }^{11}$.

Esta predilección se evidencia en las abundantes traducciones que Gagini realiza de los románticos franceses: Víctor Hugo, François Coppée y Gustave Michaud.

En cuanto a la influencia española, es evidente en sus poemas la huella de Bécquer, no sólo en cuanto a la temática, por lo demás clarísima, sino en aspectos formales: repeticiones, aliteraciones, anáforas, oposiciones, etc. Formas casi estereotipadas se manifiestan en sus poemas. En la «Rima LIII», Bécquer, utilizando como recurso la anáfora, logra una intensificación del ritmo interno del poema:

Volverán las oscuras golondrinas en tu balcón sus nidos a colgar, y otra vez con el ala a sus cristales jugando llamarán; (...)

Volverán las tupidas madreselvas de tu jardín las tapias a escalar... ${ }^{12}$

${ }^{10}$ Cfr. Emilio Carilla, op. cit., pp. 100-101.

${ }^{11}$ «Europa», en Lira costarricense, tomo II (San José, Costa Rica: Tipografía Nacional), pp. 41-48.

${ }_{12}$ Gustavo Adolfo Bécquer, Rimas, leyendas y narraciones (México: Porrúa, 1971). 
El mismo medio emplea Gagini, con resultados semejantes, en varios de sus poemas. En «iAdiós!» expresa:

¡Ya nunca volverán tus bellos ojos a reflejar mis húmedas pupilas

ni me darán consuelo en mis enojos tus miradas tranquilas!

¡Ya nunca volveré a causarte agravios de mi loca pasión en los excesos, ni aguardes en las rosas de tus labios mis adorados besos! ${ }^{13}$

Los ejemplos de la influencia que ejerce Bécquer sobre Gagini son abundantes. Semejanza no sólo en cuanto a lo formal, sino en el temple anímico. El yo lírico reclama la insensibilidad de la amada, su lejanía y desamor. Esto se resuelve, al fin, con la certeza de la soledad, talante muy propio del romántico que Gagini plasma en imágenes muy del gusto becqueriano. Veamos:

GaGrNI: Y tú que eras para siempre mía,
y puesto de rodillas te adoraba.

BÉCQUER: Pero mudo y absorto y de rodillas, como se adora a Dios ante su altar...

Sin embargo, se pueden señalar diferencias entre el escritor español y el costarricense. En Bécquer, el estado de evasión y la idealización de la mujer son más profundos. Para éste, la mujer es una pura proyección espiritual, ideal al que sólo puede acercarse a través de la evasión y el sueño. Para Gagini, la mujer es más corpórea, más tangible, más alejada del puro ideal.

Esta diversa percepción marca una diferencia en ambos poetas, especialmente en cuanto a la intensidad con que el yo lírico manifiesta el dolor y en las imágenes poéticas. Comparten la idea de que la mujer y su cercanía o alejamiento generan la felicidad o el dolor del poeta, pero Gagini percibe una mujer más cercana al mundo de sus deseos y afectos.

Abundantes son los ejemplos de las coincidencias entre ambos autores. Lo mismo puede señalarse en cuanto a Espronceda; incluso en el poema mencionado anteriormente, «El gran galeoto», aprovecha Gagini un tema puesto de moda por el escritor español.

${ }^{13}$ «Adiós!», en Vagamunderías, p. 10. 
Otra influencia del romanticismo español es la predilección por las leyendas, gusto que en Costa Rica se había robustecido por la publicación de algunas de Bécquer y de Ricardo Palma. Gagini publica una extensa leyenda versificada, «Adela» ${ }^{14}$, de tema amoroso; anteriormente también había publicado «La colina de los amantes», traducción y adaptación de una leyenda francesa, según palabras del propio autor. Por otro lado, la publicación de este tipo de relatos en las revistas y diarios de la época pone de manifiesto la moda romántica.

Para abarcar la totalidad de la producción poética de Gagini, proponemos tres etapas evolutivas, marcadas sobre todo por una mayor madurez y un mayor compromiso social del escritor. Una primera etapa en la que escribe poesía sencilla, de juventud. No sigue ninguna escuela y más bien es producto de la necesidad de expresión del escritor. Temática cotidiana inspirada en sus diversas vivencias. Sobresale en ella su capacidad de versificador ${ }^{15}$. Ejemplo de estos poemas es el titulado «Adiós a Heredia»:
¡Heredia, jarrón de flores en donde tienen las bellas la mente llena de estrellas el alma llena de amores...! 16

La métrica de estos poemas es sencilla: predominan las formas populares como el romance y el octosílabo; poesía modesta, cuyo valor es manifestar la admiración del poeta por diferentes aspectos de la vida nacional.

En segundo lugar ubicamos los poemas de influencia romántica, producto de un romanticismo tardío, fundamentalmente temático. En ellos es evidente la afinidad entre la poesía nacional y la europea y latinoamericana. Los temas, de amplia difusión en el contexto latinoamericano, son los que utiliza Gagini.

Poesía sentimental, su rasgo más sobresaliente es la idealización de la mujer amada, logrado a través de un estado de ensoñación del yo lírico. Es la evasión propia del movimiento. En ocasiones recurre a formas estereotipadas, hecho que revela el contacto del escritor con la literatura de románticos famosos.

${ }^{14}$ «Adela», en Lira costarricense, tomo II (San José: Tipografía Nacional, 1891), pp. 49-70.

${ }^{15}$ La capacidad de versificador de Gagini fue reconocida por los tres únicos críticos que se han referido a su poesía: Roberto Brenes Mesén, Elías Jiménez y Abelardo Bonilla.

${ }_{16}$ «Adiós a Heredia», en Vagamunderías, p. 21. 
En el poema «Sueños» es evidente la imitación de Bécquer y de algunos tópicos románticos:

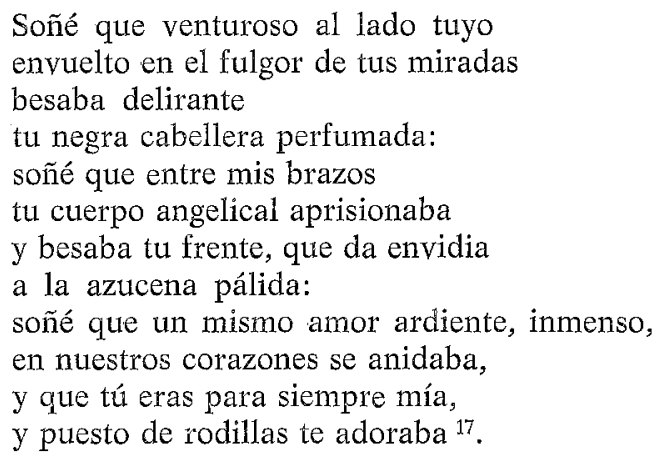

En una tercera etapa situamos la poesía de fuerte contenido social; en muchos casos son poemas de denuncia, en los que la mayor preocupación es la patria y su ubicación en un contexto mayor. Su poesía se internacionaliza y trasciende los temas amorosos. En esta época, el asunto básico es la relación de las dos Américas, tema palpitante que es discutido con ardor por un gran sector de intelectuales latinoamericanos inspirados por Martí y Rodó, especialmente. Aunque estas dos últimas etapas coexisten, y no puede señalarse un límite preciso entre una y otra, conviene señalar que los acontecimientos de 1898 radicalizaban esta generación y con ello su escritura. Por esta razón, es a partir de ese momento cuando Gagini intensifica esta temática, concluyendo en sus novelas, que cronológicamente son posteriores a su producción poética.

La gran importancia de este período, primeras décadas del siglo $\mathrm{xx}$, es que se inicia la apertura de la poesía costarricense a la poesía moderna. En este sentido, como precursores, Gagini, junto con otros poetas costarricenses, cobran visible importancia. Promueven una pronta recepción de lo que pasa en poesía, tanto en Europa como en América Latina; asumen temas poéticos del movimiento, colocando a Costa Rica dentro de una corriente intelectual importante.

Como culminación de este período sobresale la publicación, en el año de su muerte, 1925, de la colección mayor de sus poemas, reunidos en el tomo Vagamunderías, título escogido por el propio Gagini, y que evidencia, según el autor, que no se considerara poeta de oficio, sino versificador ocasional, casi como entretenimiento.

\footnotetext{
${ }^{17}$ «Sueños», en Vagamunderías, p. 19.
} 
La obra contiene veintiocho poemas, escritos en diferentes épocas de su vida, algunos publicados años antes en diversas revistas, de diferente calidad artística, pero la mayoría de inspiración romántica, aunque varios con marcada orientación social y de denuncia. Este último aspecto en la poesía de Gagini refleja el ideal político como uno de los ideales románticos. La exaltación de la libertad fue uno de los tópicos que asumió el movimiento, pues, según Guillermo Díaz-Plaja, «la sincronización exacta de los mundos de la cultura y de la política tienen en la época romántica una especial trascendencia» ${ }^{18}$. En América agudiza este estado la situación política conflictiva que se vive por la independencia de Cuba y la creciente hegemonía de los Estados Unidos. Gagini manifiesta esa actitud de precaución y hechazo ante la circunstancia que vive.

Las vivencias románticas que mantiene su poesía, y no sólo la de él, sino las de otros poetas costarricenses como Fausto Pacheco, Luis Hine, Justo A. Facio, etc., evidencian la presencia de ese romanticismo tardío en nuestras letras si comparamos a Costa Rica con el resto de América.

En el resto de América Latina, más o menos en 1867, el movimiento ha perdido fuerza; Gagini comienza a escribir en 1885, y aunque no se cuenta con datos precisos sobre la fecha de escritura de cada uno de sus poemas, se pueden ubicar entre finales del siglo $\mathrm{XIX}$ y principios del $\mathrm{xx}$, unos treinta años después de la declinación romántica en los otros países latinoamericanos. Los rasgos románticos más importantes que se pueden señalar en la poesía de Gagini son: valoración estética de lo individual y subjetivo, versión de la rebelión individualista que preconiza el racionalismo. Esta se lleva a cabo de diferente manera: el yo entra en contacto directo con un tú inasible, inalcanzable:
¿Por qué en la vida la ilusión más bella no se llega jamás a realizar y la dulce ventura que soñamos se escapa a nuestro afán? (...)
¿Por qué siempre en ti he encontrado como valla invencible tu frialdad y ¿por qué si ese amor es imposible no te puedo olvidar? ${ }^{19}$

${ }^{18}$ Guillermo Díaz-Plaja, Introducción al estudio del romanticismo español (España: Espasa-Calpe, S. A., 1936), p. 107.

19 «¿Por qué?», en Lira costarricense, p. 12. 
O bien el yo se agranda y se convierte en objeto de la expresión:

Hoy ya la fantasía

No vuela como inquieta

Traviesa mariposa

Que va de flor en flor;

Ni tiene luz la luna

Ni aroma la violeta

$\mathrm{Ni}$ vaga cual vagaba

La mente del poeta

Cantando las divinas

Dulzuras del amor ${ }^{20}$.

Por esta singular condición, el romántico siente la necesidad de definir su oficio. Como hace circular el mundo alrededor de su yo, su expresión poética es muy importante; de aquí que cada escritor plasme su concepción de la poesía y sugiera su poética. Bécquer, en varias de sus rimas, alude al poeta y a la poesía como oficio divino; en la «Rima $V$ » expresa:

Yo soy sobre el abismo el puente que atraviesa, yo soy la ignota escala que el cielo une a la tierra.

Yo soy el invisible anillo que sujeta el mundo de la forma, el mundo de la idea.

Yo, en fin, soy ese espíritu, desconocida esencia, perfume misterioso del que es vaso el poeta.

Esta misma opinión de poeta y poesía mantienen los escritores latinoamericanos; Palma, por ejemplo, en el poema «La poesía», publicado en Costa Rica Ilustrada, dice en tono irónico:

Es arte del demonio o brujería esto de escribir versos (...)

${ }^{20}$ «Desengaño», en Lira costarricense, pp. 23-29. 
Es preciso no estar en sus cabales para que un hombre aspire a poeta, pero, en fin, es sencilla la receta:

forme usted línea de medidas iguales, y luego en fila las coloca juntas poniendo consonantes en las puntas.

¿Y en el medio? ¿En el medio? ¡Ese es el cuento! Hay que poner talento ${ }^{21}$.

Gagini no es ajeno a esta posición; su poesía «El arte» valora el oficio de poeta, alaba la condición humana, que es principalmente emoción, sentimiento, sobre razón:
... mas, ¿qué belleza natural podría nunca igualar el pensamiento humano cuando en alas de ardiente fantasía el país del sueño se dilata?
El arte es uno: en mármol o en colores en acorde o palabra sus ideales el artista labra y ciñe de inmortales resplandores. ¿Qué importa el material, si la luz viva del genio dejan en él su eterno rastro? ${ }^{22}$

Para Emilio Carilla, uno de los aspectos principales del romanticismo es el valor que se le da a la libertad, libertad para todas las actitudes de la vida. En Gagini este tema se resuelve en la búsqueda de la libertad de los pueblos, tema que en América Latina es de especial importancia. No es tanto la libertad individual la que desea, sino lograr la conciencia de una libertad colectiva, en todos los campos de la sociedad. Por esa razón, condena duramente la tiranía; en 1891, en el poema «A Costa Rica», exhorta vehementemente a sus receptores:

¡Valientes ciudadanos! Hoy que alumbra

E1 sol de la verdad, y no os deslumbra con mentidas promesas un tirano...

El deseo de libertad va unido a la valoración del concepto de patria, de lo nacional. Ensalza los valores patrios y justifica la guerra como medio para preservarlos. Esta clara actitud romántica se manifiesta incluso en la

${ }^{21}$ Ricardo Palma, «La poesía», en Costa Rica Ilustrada (2." época, núm. 28, 15 mayo 1891), p. 217.

${ }_{22}$ «El arte», en Vagamunderías, pp. 23-24. 
predilección que muestra, como traductor, por la temática de la guerra. En el poema antes mencionado resume muy bien su posición:
Que el alma siempre altiva, siempre digna
Se consagre a la patria únicamente;
$Y$ con amor ardiente
Por defender sus fueros, vuestra vida
Llevad si es menester el sacrificio:
Entonces podrás ser, patria querida,
De grandeza y virtud bello edificio ${ }^{23}$.

Otro tema es el amoroso, tema central de su poesía, tan importante como el social. El amor no es tratado por el poeta únicamente en su dimensión yo-tú o de relación hombre y mujer, sino que es el motivo que le permite trascender hacia algunos problemas existenciales que le plantea su condición de ser agónico. El amor es considerado por el yo lírico como el premio y el castigo del ser humano; por eso, acude a una serie de enumeraciones para definirlo:

¿Me dijiste una vez que no has sabido

hasta hoy lo que es amor? Voy a decírtelo.

(...) nos roba las ideas y energías

nos ciega y embrutece; es un demonio

que vierte en nuestro oído

criminales consejos,

horribles tentaciones homicidas;

es la locura, el crimen, el tormento

que Dios impuso al hombre cuando quiso

saber el bien y el mal, no satisfecho

del candor celestial del paraíso ${ }^{24}$.

Este dolor del yo lírico ante una fuerza superior a él lo lleva a adoptar un tono confesional en su poesía. Como el romántico es un incomprendido, utiliza esa forma de expresión para manifestar su inconformidad y frecuentemente su soledad. En Gagini, la sensación de desengaño es dominante: es un desengaño no sólo producto de la incomprensión del tú, sino que es un desengaño de su circunstancia, de aquello y aquellos que le rodean. Quizá por cuestiones biográficas, creemos que no sólo es una actitud literaria, sino el resultado de algunos enfrentamientos ideológicos con

\footnotetext{
${ }^{23}$ «A Costa Rica», en Lira costarricense, pp. 32-40.

${ }^{24}$ «Amor (a una artista)», en Vagamunderías, pp. 17-18.
} 
otros intelectuales que no comprendieron sus puntos de vista sino en algunos pequeños artículos, especialmente cuando se aleja hacia El Salvador.

En «Desengaño», la actitud es evidente:

¡Cuánto tarda en llegar el dulce olvido

a adormecer un incurable daño

cuando nos hiere el pecho dolorido

con sus alas de hielo el desengaño! ${ }^{25}$

Muchos tópicos pueden rastrearse en su poesía; sin embargo, nos hemos limitado a los más significativos. Una consideración que no queremos dejar pasar es señalar que la poca crítica que se ha hecho sobre su poesía, en dos o tres pequeños artículos, parte de la afirmación de que Gagini no es un poeta, sino un cerebral. Nosotros no estamos de acuerdo con esta afirmación, pues el análisis de su obra poética ha probado el tono sentimental de su poesía, sus connotaciones semánticas y, frecuentemente, su lirismo.

En sus últimas composiciones es evidente su voluntad de crear, no simplemente de versificar. Conviene señalar también cierta evolución hacia modelos de la poesía vanguardista, quizá al parnasianismo, hecho que manifiesta no sólo el interés de Gagini por la cultura universal, sino su deseo de experimentar nuevas formas. El poema «Bohemio», que criticó Elías Jiménez en el prólogo de Vagamunderías, afirmando que «parece, por el descuido de la forma, más obra de bohemio que de maestro», recuerda algunas de las producciones de los escritores franceses, especialmente Verlaine.

Quizá fue la innovación lo que algunos costarricenses no aprobaron. La temática, de un fuerte pesimismo, recalca el repudio del yo lírico a una humanidad corrupta y a un mundo que no presenta ningún valor para el emisor. Se anuncian así nuevos tiempos en la poesía, novedad que, sin duda, asumirá Darío:

De codos en la mesa de un café de París, cubierta de botellas de coñac y de anís, así me habló el bohemio desgreñado y ceñudo: «Conozco de la vida las mentiras y dudo si el suelo de mi patria o la suerte de Europa, me importan más, señor, que el licor de esta copa ¡la humanidad! Rebaño inconsciente y perverso. ¡La tierra! Una molécula de un absurdo Universo,

${ }^{25}$ «Desengaño», en Vagamunderías, p. 16. 


\section{¿Y Dios? Vana quimera, engendro del temor, explotado más tarde como emblema de amor $\mathrm{Y}$ todo es en el mundo falsedad y mentira» (... ${ }^{26}$}

Señalaremos ahora algunas coincidencias más en cuanto al aspecto formal del movimiento, especialmente en la prosa.

Se dan, tanto en Europa como en América, dos tipos de prosa: la novela romántica y las autobiografías. Hay una proliferación de diarios, de memorias, en los que el escritor quiere dejar constancia de su presencia en este mundo que, por lo general, considera no lo comprendió. Gagini tiene una autobiografía y una novela romántica, La sirena, con lo que sigue las mismas huellas de los románticos. En Al través de mi vida recoge sus experiencias vitales hasta, aproximadamente, diez años antes de su muerte. Domina en la obra un tono de desengaño, que por otra parte fue constante en su poesía amorosa. En este caso, sus memorias reflejan la visión que posee de algunos intelectuales costarricenses y el rechazo que sufrió, ocasionado frecuentemente por su dogmatismo, especialmente en su concepción de la educación.

Gagini se siente incomprendido, actitud muy propia de la época. Esa incomprensión se resuelve frecuentemente en acres polémicas con otros escritores más jóvenes (Brenes Mesén, García Monge, Justo A. Facio), que no comparten sus ideas, pues han estudiado en Chile y se consideran con ideas más de avanzada. Gagini optaba por una disciplina severa.

En esta época, revistas y periódicos desempeñan un papel fundamental para la difusión de la cultura; abundaron en Europa y América artículos, firmados por un autor que se ocultaba tras un seudónimo. Clara influencia de Larra.

En Costa Rica también se llevaron a los periódicos las discusiones literarias. Gagini escribe diversos artículos, frecuentemente firmados bajo los seudónimos de «Amer» y «Kalidaza».

En cuanto a su novela La sirena, publicada en 1920, el mismo año en que aparece La caída del águila, pero con una temática completamente diferente. Pequeña obra en la que desarrolla el tema romántico de la mujer fría, incapaz de querer, que arrastra a la perdición al hombre que la ama. Con clara intención moralizante. Tiene la importancia de describir las costumbres josefinas de la clase media, y así se convierte en un cuadro costumbrista del San José de principios de siglo. Es en este sentido en el que le encontramos valor. En conclusión, son muchos los puntos de contacto entre las letras costarricenses, y específicamente entre Gagini y el movimiento romántico. Esto nos permite afirmar que si hubo un roman-

${ }^{26}$ «Bohemio», en Vagamunderias, pp. 53-54. 
ticismo, no tan consolidado como en el resto de Hispanoamérica, quizá más bien se puede hablar de preferencias románticas en la obra poética de Gagini y de otros escritores, aunque siempre haciendo hincapié en el retraso cronológico. Otro aspecto importante es que no se puede ver la producción poética del escritor costarricense como hija de su deseo de versificar únicamente. Sí existe en él una conciencia creadora, un conocimiento de las corrientes culturales del momento y un deseo de imitar los rasgos sobresalientes del romanticismo. 
